\title{
Negotiating Relationally: \\ The Dynamics of the Relational Self In Negotiations
}

Michele J. Gelfand

Virginia Smith Major

Jana L. Raver

Lisa H. Nishii

Karen O'Brien

Working Paper 07 - 06 


\title{
Negotiating Relationally: The Dynamics of the Relational Self In Negotiations
}

\author{
Michele J. Gelfand \\ University Of Maryland \\ Virginia Smith Major \\ University Of Maryland \\ Jana L. Raver \\ Queen's University \\ Lisa H. Nishii \\ Cornell University \\ Karen O'brien \\ University of Maryland
}

February 2007

http://www.ilr.cornell.edu/cahrs

This paper has not undergone formal review or approval of the faculty of the ILR School. It is intended to make results of Center research available to others interested in preliminary form to encourage discussion and suggestions.

Most (if not all) of the CAHRS Working Papers are available for reading at the Catherwood Library. For information on what's available link to the Cornell Library Catalog:

http://catalog.library.cornell.edu if you wish. 


\begin{abstract}
Although negotiation research is thriving, it has been criticized as having an arelational bias-emphasizing autonomy, competition, and rationality over interdependence, cooperation, and relationality. In this article, we advance a new model of relationality in negotiation. Drawing on research in social psychology, we describe the construct of relational self-construals (RSC) and present a temporal model of RSC and negotiation. After delineating the conditions through which RSC becomes accessible in negotiation and conditions that inhibit its use, we discuss how RSC affects negotiators' pre-negotiation psychological states, early and later tactics, and negotiation outcomes. We illustrate a number of distinct relational dynamics that can occur based on the dyadic composition of RSC, each of which brings distinct benefits and costs to the negotiation table. Implications for the science and practice of negotiation are discussed.
\end{abstract}

\title{
In Press, Academy of Management Review
}

ACKNOWLEDGEMENT: We express our gratitude to Beta Mannix, three anonymous reviewers, Katherine Klein, Arie Kruglanski, and Chuck Stangor for their insightful comments on the manuscript. Correspondence regarding this article can be sent to mgelfand@psyc.umd.edu. 


\section{Negotiating Relationally: The Dynamics of the Relational Self In Negotiations}

Research on negotiation is thriving. Over the last two decades, scholars have greatly advanced our understanding of basic psychological processes in negotiation, including negotiator cognition (e.g., Neale \& Bazerman, 1991; Thompson \& Hastie, 1990), motivation (e.g., De Dreu \& Carnevale, 2003), and emotion (e.g., Allred, Mallozzi, Matsui, \& Raia, 1997; Barry \& Oliver, 1996; Morris \& Keltner, 2000; Thompson, Medvec, Seiden, \& Kopelman, 2001). Great strides have also been made in understanding complex social processes in negotiation, such as communication (e.g., Weingart, Prietula, Hyder, \& Genovese, 1999), and power and influence (e.g., Ebenbach \& Keltner, 1998; Mannix, 1994). Likewise, research has provided insights into the impact of the negotiation context-such as teams, third parties, and technology—on negotiation dynamics (e.g., Croson, 1999; McGinn \& Keros, 2002; Thompson, Peterson, \& Kray, 1995). Indeed, research is shedding new light on topics that previously were at a "dead end." For example, not long ago, personality was seen as lacking much explanatory value in negotiation, yet recently there has been a resurgence of interest on this topic (Barry \& Friedman, 1998). More generally, few areas in organizational behavior have developed as rapidly, and with as much depth and breadth, as the field of negotiation (Kramer \& Messick, 1995).

Nevertheless, research on negotiation has not gone without criticism. Numerous scholars have bemoaned that the field offers a largely arelational view of an inherently relational situation. In an early critique, Barley (1991) questioned whether findings, largely drawn from simulated negotiations between unacquainted participants, correspond to the dynamics of real world negotiations in which prior relationships figure so prominently. Later, Gray (1994) cogently argued that many of the field's meta-assumptions reflect an arelational biasemphasizing autonomy, competition, and rationality over interdependence, cooperation, and relationality. Other scholars have echoed these sentiments, arguing that traditional negotiation research does not adequately capture relational dynamics in negotiation (Greenhalgh \& Gilkey, 
1993; Greenhalgh \& Chapman, 1995; Kolb \& Coolidge, 1991). Yet despite this void, rich theoretical and empirical work on relational constructs is still lacking in the literature. As discussed below, although there has been some discussion of relational orientation in negotiation (e.g., Greenhalgh \& Gilkey, 1993; King \& Hinson, 1994; Rubin \& Brown, 1975), this construct has remained relatively ill-defined, and its constituent psychological and social processes in negotiation remain unexplored. In short, although criticisms regarding the arelational nature of negotiation theory are certainly valid-and we suspect that many scholars would agree with these arguments-they have nonetheless largely remained abstract, offering little in the way of a concrete research agenda for the field.

In this article, we advance a more comprehensive theory of relationality in negotiation. At the core of our model is the construct of the relational self-construal (RSC). As we detail below, in the last two decades, there has been a proliferation of research in social psychology on the self in general, and the relational self in particular (e.g., Andersen \& Chen, 2002; Baldwin, 1992; Brewer \& Gardner, 1996; Chen, 2001; 2003; Chen, Lee-Chai, and Bargh, 2001; Cross, Bacon, \& Morris, 2000; Cross \& Morris, 2003; Cross, Morris, \& Gore, 2002; Cross \& Madson, 1997; Gabriel \& Gardner, 1999; Kashima, Yamaguchi, Kim, Choi, Gelfand, \& Yuki, 1995; Sanchez-Burkes, 2002). In contrast to a view of the self as largely independent, RSC reflects a cognitive representation of the self as fundamentally connected to other individuals (Cross \& Madson, 1997; Kashima et al., 1995). It has been linked to an impressive array of psychological processes, including attention, memory and inference (e.g., Gabriel \& Gardner, 1999), emotional regulation and expression (e.g., Cross et al. 2000; Cross \& Madson, 1997), and motivation (e.g., Cross et al., 2000; Gardner, Gabriel, \& Hochschild, 2002). RSC has also been implicated in a wide range of social processes that are aimed at cultivating and preserving relationships, including partner choice, communication and self-disclosure, decision-making, and behavior (e.g., Cross et al., 2000; 2002; Gabriel \& Gardner, 1999). Yet despite these farreaching and exciting theoretical and empirical developments, discussions of RSC have 
remained isolated from the field of organizational behavior in general, and the field of negotiation in particular.

We begin filling this void by advancing a dynamic theory of RSC and negotiation. In what follows, we first define key terms regarding the self in order to provide necessary grounding for our model of RSC and negotiation. Next, we delineate the construct of RSC, and how it is implicated in cognitive, emotional, and motivational processes. Third, we present our integrative model of RSC and negotiation. Viewing negotiation through a temporal lens, we delineate the processes through which RSC becomes accessible in negotiation and the conditions that inhibit its use. We then illustrate the ways in which RSC affects negotiators' prenegotiation psychological states, early and later tactics, and negotiation outcomes. As we will show, there are a number of distinct relational dynamics that can occur based on the dyadic composition of RSC, each of which brings distinct benefits and costs to the negotiation table. We conclude with a discussion of the implications of the model for negotiation theory and practice.

\section{Key Terms}

The self is defined as a multidimensional, dynamic knowledge structure that organizes self-relevant information (Cross et al., 2002; Markus, 1977; Markus \& Wurf, 1987). It is comprised of multiple self-representations—what have been termed self-schemas or selfconstruals—which embody knowledge about oneself, including "personality attributes, social roles, past experience, future goals, and the like" (Fiske \& Taylor, 1991: 181-182). Some selfconstruals are especially central, well elaborated, and important to an individual; others are less important and are more peripheral (Fiske \& Taylor, 1991).

Although we possess a large repertoire of self-construals, social cognition scholars have long argued that only a limited number of these are in use at any point in time (Markus \& Kunda, 1986; Markus \& Wurf, 1987; McGuire, McGuire, \& Cheever, 1986). More specifically, selfknowledge can be available in memory but unless it is accessible it will not be used to process 
information. Accessibility refers to the potential for stored knowledge to be used to respond to stimuli (Bruner, 1957; Higgins \& King, 1981; Higgins, 1996). The greater the accessibility of an attribute, the more self-defining that attribute is for an individual (Higgins, 1996; Higgins, Shah, \& Friedman, 1997; Shah, Higgins, \& Friedman, 1998). The accessibility of self-construals can be derived from two distinct sources. Self-construals are likely to become chronically accessible the more frequently and consistently individuals use such attributes to define the self. Selfconstruals can also be temporarily accessible when strong features of a situational context impinge on an individual and temporarily increase accessibility of self-knowledge (Kihlstrom \& Cantor, 1984). Accessibility of a construct is an additive function of chronic and temporary accessibility (Bargh, Bond, Lombardi, \& Tota, 1986; Higgins, 1989). That is, the effect of accessibility in a particular situation depends solely on its strength of accessibility-the source of the accessibility, temporary or chronic, is irrelevant (Higgins, 1996).

Importantly, accessibility does not automatically translate into knowledge use. Rather, there may be inhibitory processes that prevent knowledge that is accessible from being used, and call for more relevant knowledge to be used instead. An important variable that influences whether stored knowledge will actually be used is the fit or applicability of the knowledge to the stimulus (Higgins, 1996). As Higgins (1996: 154) explains, "The greater the overlap between the features of some stored knowledge and the attended features of a stimulus, the greater is the applicability of the knowledge to the stimulus and the greater is the likelihood that the knowledge will be activated in the presence of the stimulus." Applicability involves an unconscious assessment of the relevance of an accessible construct to the context; if the knowledge structure is not relevant, it won't be used (Higgins, 1996). For example, an individual for whom the construct of aggressiveness is accessible will not actually use that construct to guide thoughts, feelings, or behavior unless the stimulus has aggressive cues (i.e., it is applicable to the knowledge structure). An exception to this rule, however, is if an individual has extremely strong accessibility of a construct; Very strong accessibility can compensate for weak 
applicability (Higgins \& Brendl, 1995). Furthermore, individuals may also consciously decide not to use accessible knowledge if the accessible knowledge is deemed to have low "judged usability" (Higgins, 1996). As Higgins (1996: 136) notes: "Even when stored information is activated because of its accessibility and applicability to a stimulus, it might not be consciously used if it is perceived as irrelevant or inappropriate." Importantly, conscious processing due to judged usabilty occurs "after knowledge activation but before knowledge use" (p. 152; italics in original) (see also Devine, 1989, Kruglanski, 1989).

Finally, once they are in use, self-construals are a powerful regulator of human behavior. Self-construals have a critical influence on information processing about oneself and other people, affecting perception, memory, attributions, and inferences (Fiske \& Taylor, 1991; Markus, Smith, \& Moreland, 1985). The self also has a profound influence on emotion and affect regulation (Cross \& Madson, 1997). For example, self-construals determine what triggers individuals' emotional reactions to a stimulus event. When an aspect of the self is affirmed through an event, positive emotions result, whereas when an aspect of the self is threatened, negative emotions follow (Higgins, 1987). The self is also intricately tied to motivation and selfregulation. Self-construals direct our actions as we consciously or unconsciously engage in tactics to "self-verify" or confirm our conceptions of ourselves (Swann, 1987). Individuals set goals that are consistent with their self-construals, engage in behaviors to fulfill those goals, and monitor their accomplishments very closely (Carver \& Scheier, 1981).

\section{RELATIONAL SELF-CONSTRUALS}

For much of the past century, research on the nature and consequences of selfconstruals has largely focused on the independent self-the conception of oneself as an autonomous and unique entity (Bakan, 1966; Parsons, 1949; Markus \& Kitayama, 1991; Triandis, 1989). Independent self-construals have been associated with a sense of personal agency, a focus on the self as separate from others, and a belief that the self is generally dissimilar to others (Shweder \& Bourne, 1982). In recent years, however, research has shown 
that this prevailing self-construal provides a rather limited perspective on the nature and consequences of the self. In contrast to a focus on independence, a proliferation of research has shown that individuals can emphasize the relational self-a view of the self as fundamentally connected to other individuals (e.g., Andersen \& Chen, 2002; Aron, Aron, \& Smollman, 1992; Brewer \& Gardner, 1996; Chen, 2001; 2003; Chen et al., 2001; Clancy \& Dollinger, 1993; Cross, et. al, 2000; 2002; Cross \& Morris, 2003; Cross \& Madson, 1997; Gilligan, 1982; Kashima et al, 1995; Kashima \& Hardie, 2000). Rather than emphasizing individual autonomy and promotion of one's own goals, in this self-construal, the priority is to emphasize "connectedness to others and [to] behave in ways that promote and strengthen existing relationships" (Cross, et al., 2002: 400). Moreover, as detailed below, when connections with others figure prominently in one's representations of the self, it is relationships - and not one's personal attributes-that provide a critical framework through which cognition, emotion, and motivation are regulated. Table 1 summarizes the following discussion of these relational cognition, emotion, and motivational processes.

Table 1

Relational Self-Construal and Associated Psychological Processes

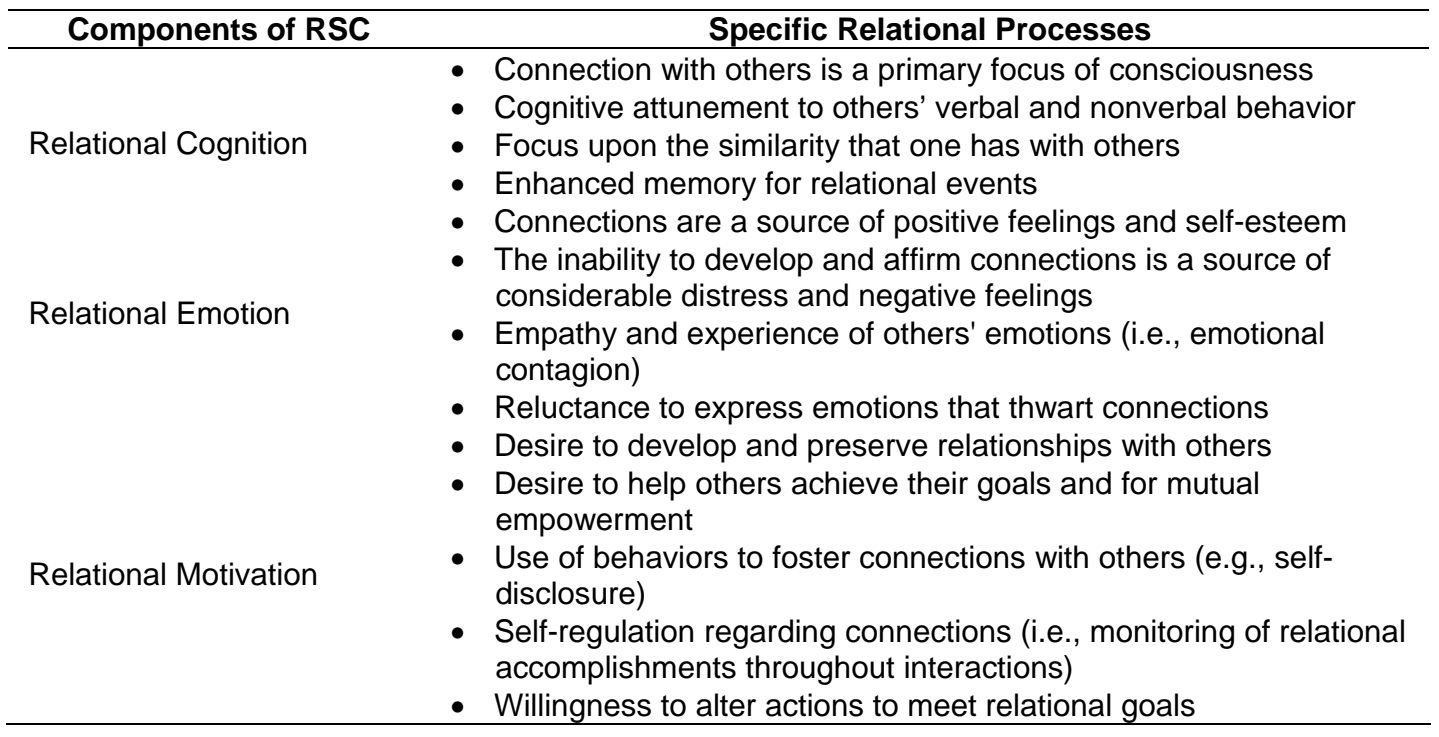


Relational Cognition. As with other aspects of the self, RSC provides a framework through which information is filtered, processed, and remembered. These processes are referred to as "relational cognition," as they all implicate the self in connection with others. When RSC is accessible, the connections one has with others are very salient (i.e., one's thoughts focus on how much the self is connected with others), and individuals are more likely to notice, encode, and process stimuli that have implications for their ability to cultivate a connection with others (Cross \& Madson, 1997; Cross et al., 2002). Accordingly, RSC accessibility is related to an increased sensitivity to others' verbal and nonverbal behavior (Jordan, 1997; Markus \& Oyserman, 1988; Sanchez-Burks, 2002), and a heightened awareness of others' goals and interests (Cross \& Madson, 1997; Cross et al., 2000). As noted by Cross and Madson (1997: 81), attentiveness to such information is helpful in the maintenance of relationships with others, because "[once] one has carefully attended to another's thoughts and feelings, one should be more likely to behave in a fashion that demonstrates empathy and support." RSC is also related to an increased focus on the similarity that one has with others. For example, Cross et al. (2002) found that people with RSC accessibility were more likely to rate close others as being similar to themselves in terms of abilities, traits and beliefs. This notion is also consistent with research that has shown that perspective taking increases the overlap between representations of the self and others (Galinsky \& Moskowitz, 2000; see also Davis, Conklin, Smith \& Luce, 1996), which is likely to be higher among those with RSC accessible. More generally, perceptions of similarity of the self and other affirm the connection within a relationship, facilitate harmony, and affirm the value of one's own attributes (Cross et al., 2002). Finally, consistent with enhanced memory functions of the self, research has shown that RSC affects memory for relational events. For example, Cross et al. (2002) found that RSC was related to the degree to which people recalled relational information about a target and the degree to which they organized information about others in memory based on their 
relationships. Having a highly organized cluster of relational information enables individuals to notice, encode, and process relationship information with greater speed and ease.

Relational Emotion. RSC is intricately related to emotional functioning, including the eliciting conditions of emotions (i.e., what triggers an emotional response) and the types of emotions experienced (Markus \& Kitayama, 1991). These processes are referred to as "relational emotion," since they are filtered through a focus on connection with others. When RSC is accessible, connections with others are highly salient and can trigger positive or negative emotions. In particular, the ability to develop and affirm connections with others is a major source of positive emotions and self-esteem for those with RSC accessible, whereas the inability to develop and affirm connections with others is a major source of negative emotions (Cross et al., 2002). For example, individuals with RSC accessible may feel considerable anxiety or distress as a result of conflict with a friend or lack of connection with an acquaintance with whom they expected a connection (Cross \& Madson, 1997). Indeed, thwarted connections can elicit anger and retaliation among those with RSC accessible. For example, in situations wherein one expects another to behave relationally, yet the other does not reciprocate the relational efforts, individuals with RSC accessible are likely to behave in subtle, covert, but aggressive ways that conceal their true intentions-a phenomenon that has been referred to as relational aggression (Cross \& Madson, 1997; Talbot, 2002). Finally, RSC is also related to other emotional experiences. For example, individuals with RSC accessible will have greater empathy for others' emotions, and may experience "vicarious" emotional experiences of others (i.e., "emotional contagion") (Cross \& Madson, 1997). Individuals with RSC accessible are also likely to avoid the expression of certain emotions that can thwart connections. For example, unless others have reneged on their relational obligations (as discussed above), individuals with RSC accessible are likely to be reluctant to express negative emotions (e.g., anger) which might damage relationships (Cross \& Madson, 1997). 
Relational Motivation. Lastly, RSC is also implicated in motivation and self-regulation. Connections with others become the framework through which individuals are motivated to action-processes that are referred to as "relational motivation." RSC accessibility is positively associated with the desire to develop and affirm relationships, and is related to the use of tactics to foster connections with others (Cross \& Madson, 1997). For example, RSC accessibility is associated with personal self-disclosure, which helps to foster rapport (Cross et al., 2000). Moreover, RSC is related to motivations for "mutual empowerment"-a desire for mutual support and aid in relationships (Fletcher, 1996; Jordan, 1997; Kolb \& Coolidge, 1991)—and is also associated with seeking to help others achieve their goals (Fletcher, 1996; Gabriel \& Gardner, 1999). For example, Cross et al. (2000) demonstrated that RSC is related to the willingness to take others' needs, opinions, and wishes into account when making an important decision. Helping others succeed is often a goal in and of itself, leading to a sense of personal empowerment, even if doing so is at the expense of one's own needs (Fletcher, 1996; Kolb \& Coolidge, 1991). Finally, consistent with the self-regulatory function of the self, RSC is related to relational monitoring; individuals for whom RSC is accessible will monitor their relational accomplishments very closely throughout their interactions, and will change their actions in order to meet relational goals. This is consistent with Surrey's (1991) argument that the relational self includes the capacity to consider one's actions in light of others' needs and feelings.

Divergence from Other Constructs. While we have focused on the processes associated with RSC, it is worth noting what RSC is not, or in other words, how it diverges from other constructs in the literature. For example, RSC is distinct from other aspects of the self that have been linked to culture, namely the individualistic and collectivistic aspects of the self (Gabriel \& Gardner, 1999; Kashima et al., 1995; Kashima \& Hardie, 2000). For example, Kashima et al. (1995) empirically differentiated between three different dimensions of the self that are often confused in the literature: the individualistic dimension of the self, which refers to 
the self as an independent, autonomous, and agentic entity; the relational dimension of the self, which refers to the extent to which people regard themselves as emotionally connected to other individuals; and the collective dimension of the self, which refers to the self in relation to a group or collective. The latter emphasizes group affiliation, in-group norms, and statuses defined by collectives (E. Kashima \& Hardie, 2000; Tajfel \& Turner, 1979; Triandis, 1989). Data from five countries showed that these three aspects of the self are indeed distinct constructs.

Constructs in the negotiation literature that also share some overlap with RSC include interpersonal orientation (Rubin \& Brown, 1975), prosocial motives (Van Lange, 1999), otherconcern (Pruitt \& Rubin, 1986), relationship orientation (Greenhalgh \& Gilkey, 1993) and relationship preference (King \& Hinson, 1994). All of these constructs share an emphasis on being concerned about others, yet none capture the breadth and depth of RSC. For example, Rubin and Brown's (1975) "interpersonal orientation" refers to someone who is attuned to variations in another's behavior. This construct has some overlap with the cognitive component of RSC, yet it is not conceptualized as an aspect of the self, nor does it have linkages to multiple psychological processes. Interpersonal orientation also includes extraneous elements not related to RSC. For example, the measure includes questions regarding individuals' willingness to engage in unethical behavior (i.e., not buying something that was stolen) (Swap \& Rubin, 1983). Likewise, Greenhalgh and Gilkey's (1993) "relationship orientation," King \& Hinson's (1994) "relationship preference," and Kolb and Coolidge's (1991) consideration of a feminist model of the relational self in negotiations share some overlap with RSC in that all are concerned with cultivating relationships. However, unlike RSC, these constructs have generally not been implicated in information processing, emotions, motivation and self-regulation (see Table 1), nor have they been linked to conditions of knowledge activation (e.g., temporary and chronic accessibility, inhibitory processes).

Finally, prosocial motives (Van Lange, 1999) as well as other concern (in the dual concern model, DCM; Pruitt \& Rubin, 1986) share some aspects of the motivational component 
of RSC in that they all emphasize concern for others. Yet while concern for others' outcomes is one goal associated with RSC, the relational motivation component of RSC is broader in that it includes relational goals such as a concern for connection and the accumulation of relational capital in negotiation (discussed below), in addition to other motivational processes (e.g., selfregulation, relational monitoring, mutual empowerment). As part of the self-system, RSC also captures other psychological processes that are not included in the DCM or social motive theory. For example, the DCM and theory on prosocial social motives do not explicitly make predictions regarding the nature of relational cognition (e.g., tracking of verbal and nonverbal cues, enhanced memory for relational events) or relational emotion (e.g., emotional contagion, distress when connections are thwarted, relational aggression). As we discuss below, with the RSC construct, we see how a refusal to establish a connection can be perceived as an affront to one's self-concept, thereby leading some negotiators to become angry and engage in relational aggression. Finally, because RSC is grounded in dynamic theories of the self, our model of RSC and negotiation includes knowledge activation processes that are not included in these other models. In this way, as we discuss below, we extend the DCM and social motives theory by providing an understanding of the conditions that lead relational concerns to be prominent or inhibited in negotiations. More generally, RSC provides a complementary perspective that adds to existing constructs in the literature.

Summary. In sum, there is substantial evidence demonstrating that RSC has implications for information processing, emotion, motivation, and resulting behavior. Despite the wide-ranging theoretical and practical ramifications of RSC, however, scholars have not yet delineated how RSC influences complex and dynamic social contexts such as negotiation, and conversely, scholars studying negotiation have not drawn from the extant research on the nature of the relational self. As we seek to show below, an integration of RSC theory and negotiation begins to address criticisms of the arelationality of negotiation theory and research, illuminates new phenomena that have yet to be examined in negotiation, begins to integrate 
research on a variety of issues through a common set of principles, and ultimately has promise for expanding the theory and practice of negotiation.

\section{The Dynamics Of Relational Self-Construals In Negotiation}

In Figure 1, we present our model of RSC in negotiations. In our model, negotiation is viewed through a temporal lens which involves a series of stages: 1) pre-negotiation conditions that affect the accessibility of RSC and inhibit its use, as well as the influence of RSC on negotiators' pre-negotiation psychological states; 2) early stages of the negotiation, including negotiators' first offers, initial concessions, and tactical behavior; 3) later stages of the negotiation process, including the creation and claiming of value; and 4) resultant distal outcomes of economic and relational capital, as well as compliance with agreements (cf. Barry \& Oliver, 1996). Although we first focus on the individual negotiator as the unit of analysis, we later argue that RSC congruency between negotiators is an important determinant of the way in which RSC ultimately affects negotiation outcomes. 
Figure 1

Negotiating Relationally: Dynamics of RSC in Negotiation

RSC Accessibility

In Negotiation
Pre-Negotiation Psychological States and Initial Tactical Behavior
Later Tactical Behavior, Negotiation Outcomes, and Post-Settlement Compliance

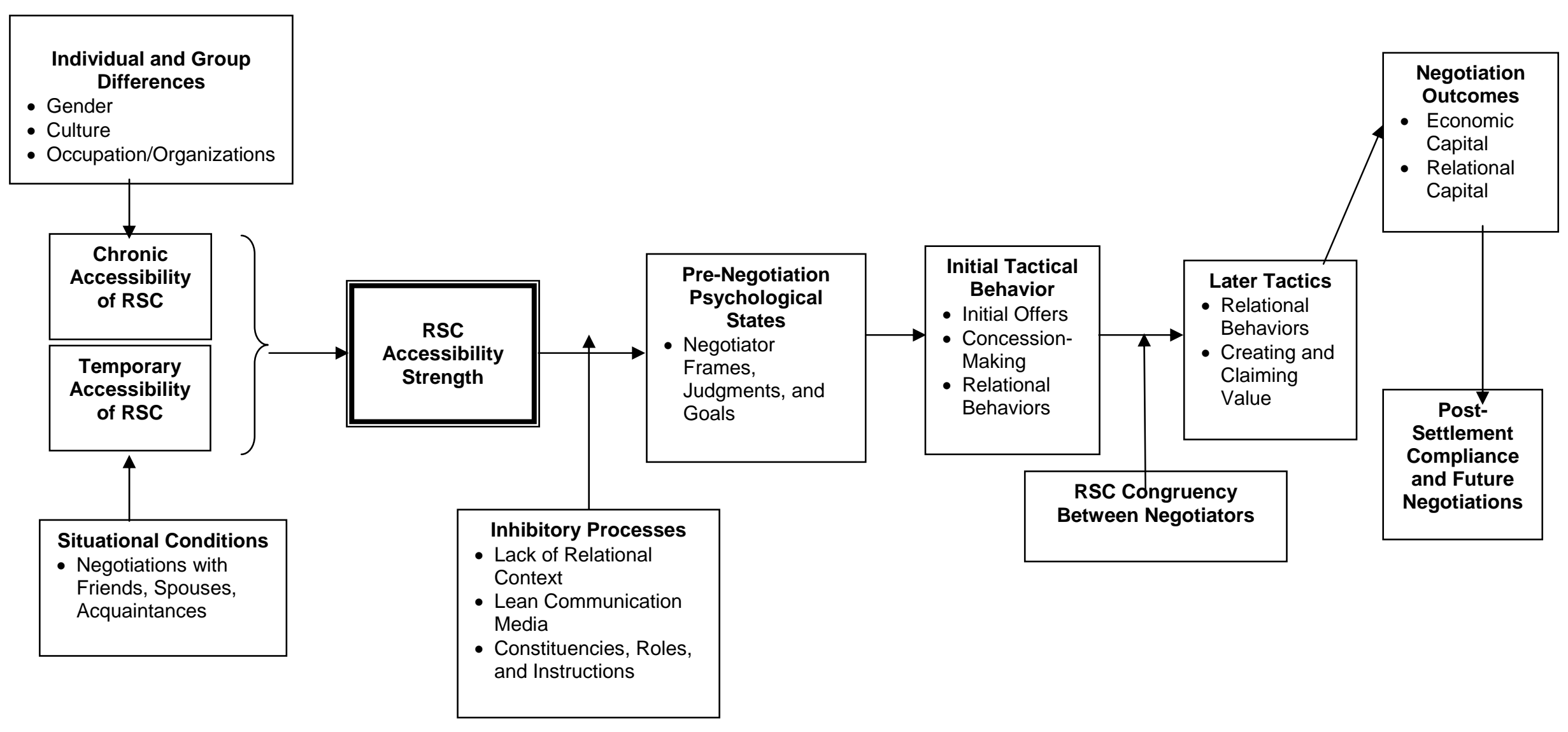




\section{RSC Accessibility and Inhibitory Processes}

Our model begins with a formulation of the factors that affect RSC use in negotiation contexts. As seen in Figure 1, we posit that there are multiple factors that can increase chronic and temporary accessibility of RSC in negotiation. However, consistent with literature on the processes leading to knowledge use, we illustrate that even if RSC is accessible, a number of inhibitory factors can suppress its actual use before a negotiation begins.

Chronic accessibility of RSC in negotiations. As noted previously, chronic accessibility of a self-construal is a function of repeated experiences and roles that are enacted over time. At the individual level, individuals who have had experiences and roles that have continuously reinforced RSC will have chronically accessible RSC. Additionally, to the extent that experiences and roles are shared, there can also be group differences in chronic RSC accessibility. This has been demonstrated for gender, with women generally scoring higher on RSC and its associated processes than men (e.g., Cross et al., 2000; Gabriel \& Gardner, 1999). In addition, although research shows that gender accounts for more variance than national culture in the relational self (Kashima et al., 1995), culture may also affect the degree to which RSC is chronically accessible. Kashima et al. (1995) found that Koreans (males and females) were much more relational than other Pacific Rim groups, which is consistent with indigenous perspectives on the pivotal role of woori (connection between 'us') in Korean society (Choi, Kim, \& Choi, 1993). Likewise, the relational self is also emphasized in Latin America among males and females alike, reflected in the notion of "simpatía," or a concern with the socio-emotional aspects of interactions (Sanchez-Burks, Nisbett, \& Ybarra, 2000; Triandis, Marin, Lisansky, \& Betancourt, 1984). Finally, group differences in RSC chronic accessibility may also arise along occupational and organizational lines. In organizational contexts where there are strong and pervasive routines, practices, and norms that prescribe that it is important to develop strong connections with others (e.g., Southwest airlines, Gittell, 2003), RSC will be more likely to be chronically accessible. Relational norms may also be strong in companies that have a strong 
"climate for service" (Schneider, White \& Paul, 1998), in which employees are expected to develop strong connections with potential customers.

Temporary accessibility of RSC in negotiations. Consistent with the social cognition literature, our model illustrates that certain negotiation conditions can temporarily increase accessibility of RSC. We posit that situations in which individuals are negotiating with close friends or romantic partners will temporarily increase the accessibility of RSC among negotiators. Such conditions-where there is a strong bond between negotiators and the expectation of ongoing interdependence—will make salient or "prime" the importance of connectedness to others and the desire to protect and maintain such connections; accordingly, the relational self is expected to be more accessible. More generally, we posit that the greater the strength of ties, the stronger the RSC accessibility in negotiations. For example, RSC accessibility is expected to be very strong in negotiations among lovers and close friends, moderately strong in negotiations among friends, and somewhat strong in negotiations among acquaintances who have to work together in the future. This is consistent with previous research that has shown that negotiations among romantic partners and close friends are especially focused on building solidarity, minimizing conflict and tension, and prioritizing the relationship over substantive outcomes (Fry, Firestone, \& Williams, 1983; Schoeninger \& Wood, 1969; Thompson, Peterson, \& Brodt, 1996), as well as with research on expected future interdependence, which finds that negotiators become more concerned about others' outcomes in such conditions (Pruitt \& Carnevale, 1993).

In Figure 1, we denote that temporary and chronic sources of RSC combine additively (Bargh et al., 1986) for an overall strength of RSC accessibility, which will be related to a host of pre-negotiation psychological states, and in turn, early and late tactics, and ultimately negotiation outcomes. However, as noted previously, accessibility does not automatically translate into knowledge use. Before turning to a discussion of how RSC affects negotiators' 
pre-negotiation states, we discuss factors that may inhibit the use of accessible RSC in negotiations.

Inhibitory processes affecting accessible RSC in negotiations. As discussed, an important factor that influences whether a knowledge structure, such as RSC, is in fact used is the degree to which there is a match between the features of the knowledge structure and features of the situation. Even if RSC is accessible, when there is not a match, the knowledge structure will not be used in that particular situation (Higgins, 1996). Accordingly, RSC is relevant only in situations that are applicable to RSC—-situations in which meaningful connections are possible. It follows that when features of the negotiation context render such connections highly irrelevant, RSC usage (and its associated psychological processes) will be attenuated. This attenuation of RSC use is particularly important to consider for people for whom RSC is high due to chronic accessibility. Our model posits that even when RSC is chronically accessible, if there is a complete lack of relational context between negotiators, as in one-shot interactions with strangers, RSC use is likely to be attenuated. RSC use is also likely attenuated when the other negotiator has very little relational presence and communication is highly restricted, as when negotiators are interacting over lean text media such as electronic mail. As McGinn \& Croson (2004) note, when communicating through email, negotiators have little social awareness of their counterparts because this medium is low in synchronicity (i.e., is low in feedback and has poor immediacy of the other party), and is highly restricted in terms of conveying paralinguistic and relational cues. As a result, without explicit relational interventions (e.g., to form connections), interactions over email tend to be highly impersonal (Moore, Kurtzberg, Thompson, \& Morris, 1999). Thus, in highly restricted relational contexts, accessible RSC is expected to be attenuated.

Indirect support for this proposition can be found in the negotiation literature. As discussed previously, women have generally been found to have greater chronic accessibility of RSC. Our model posits that negotiation conditions that render connections irrelevant or 
impossible would reduce RSC usage and would possibly reduce gender differences in negotiation. Although there is no direct assessment of this proposition, in an exploratory analysis, Stuhlmacher and Walters (1999) found that gender effects in negotiation were smaller in studies in which there was no interaction outside of the experiment as compared to studies in which future interaction could reasonably be expected. Likewise in support of the notion that restricted communication media attenuate RSC usage and thus should reduce gender differences, another meta-analysis (Walters, Stuhlmacher, \& Meyer, 1998) found that gender differences were reduced in experiments involving matrix games, in which bargainers had little direct communication, and were more pronounced in experiments involving explicit bargaining, where face-to-face communication was allowed. Consistent with aforementioned social cognition research (e.g., Higgins \& Brendl, 1995), however, it is worth noting that very strong RSC accessibility can override weak applicability situations. Thus, for example, we would expect that in situations wherein individuals with chronically accessible RSC are negotiating with friends or with people with whom they are highly interdependent-situations in which RSC accessibility is maximized due to both chronic and temporary sources-accessible RSC would still be used even if the other party has little relational presence (e.g., negotiations are taking place through electronic mail).

Finally, consistent with Higgins's (1996) discussion of conscious processes and judged usability, negotiators can also consciously choose to inhibit their accessible RSC if they judge its use to be inappropriate. For example, in situations where negotiators receive explicit instructions from others (or perceive implicit demands) to "take up" a different self, the use of RSC is likely to be actively inhibited. Such demands are often linked to role-based expectations that individuals have when negotiating for constituents. For example, research has found that negotiators who are representing others assume that their constituents want them to behave competitively (Benton \& Druckman, 1973; Diekmann, 1997; Gelfand \& Realo, 1999; Gruder, 1971). In other words, when negotiating for others, the situation can create strong alternative 
implicit (or explicit) demands that can inhibit RSC use. Some support for this notion can also be seen in research on negotiation. For example, Riley and Babcock (2002) found that women were much less cooperative when they were representing mixed gender dyads others as compared to situations in which they were representing themselves, which could possibly be mediated by inhibition of RSC accessibility. More generally, directions given to negotiators, from constituents, supervisors, and even experimenters, can inhibit RSC use in negotiations.

With these contextual antecedents and moderators in mind, we now discuss the dynamics that occur when RSC, is, in fact, in use in negotiation (i.e., RSC is both accessible and is deemed relevant to the context). Consistent with theory suggesting RSC accessibility is a continuous variable (Higgins, 1996; Higgins \& Brendl, 1995; Shah et al. 1998), we discuss how the strength of RSC accessibility affects negotiators' pre-negotiation psychological states and early tactics. We then discuss how both the strength of RSC and the congruency of RSC within dyads are related to later tactics, and ultimately, to negotiation outcomes.

\section{RSC and Negotiators' Pre-Negotiation Psychological States and Initial Tactical Behaviors}

We previously described how the relational self affects basic psychological processes such as cognition, motivation, and emotion. In this section, we expand this discussion by illustrating how RSC affects negotiators' cognitive frames, judgment biases, and goals prior to entering a negotiation. Whereas extant negotiation research often portrays negotiators as selfinterested actors, we present a divergent view of negotiators—one that highlights relational frames and judgment biases and goals for the accumulation of relational capital.

Relational frames and judgments. Negotiation scholars have long argued that individuals construct mental representations of negotiations, or conflict frames, that help them make sense of negotiation situations. We argue that self-construals, which affect perception and are critical in lending meaning to social situations (Kilhstrom \& Klein, 1994; Fiske \& Taylor, 1991), will influence negotiators' conflict frames. This is consistent with the prevailing assumption in negotiation research that previously-developed knowledge structures are used as 
individuals try to make sense of novel situations (Thompson, Neale \& Sinaceur, 2004). More specifically, when RSC is accessible, individuals are likely to view negotiations through what Pinkley (1990) termed relationship and cooperative frames-that is, they will perceive negotiations as opportunities to affirm and strengthen the relationship through cooperation.

In addition to cognitive representations of the specific negotiation situation, RSC will be related to construals of the context in which the negotiation is embedded. Negotiators for whom $\mathrm{RSC}$ is accessible will perceive the context as socially and temporally embedded-that is, they will be more likely to perceive that the social context extends beyond the immediate dyadic relationship, and the temporal context is continuous and extends considerably into in the future (cf. Greenhalgh \& Gilkey, 1993; Kolb \& Coolidge, 1991) than negotiators for whom RSC is not accessible. First, with regard to the social context, when RSC is accessible, negotiators will be more likely to perceive that they are connected to others with whom their counterparts are related, or in other words, they will construe that their interactions with their counterpart can also have ramifications for their relationships with others. For example, in negotiations with an HR representative, those with RSC accessible may assume that what happens in that setting may have implications for their relationships with others associated with the representative. Second, with regard to the temporal context, when RSC is accessible, negotiators are likely to view the negotiation with an eye for how it might affect their future relationship with their counterparts. Greenhalgh and Gilkey (1993), for example, found that relationship-oriented negotiators were more likely to regard interactions as "events within a long-term relationship" rather than to focus on the exigencies of the immediate transaction. As a result, individuals with RSC accessible will be likely to believe that what happens in the current situation will be remembered in the future (cf. Greenhalgh, 1987). It is worth noting that the effect of RSC accessibility on temporal frames is independent from our hypothesis that conditions of future interdependence are linked to temporary RSC accessibility. In the latter case, a situational condition serves as a 'stimulant" which activates stored knowledge, whereas in the former case, stored knowledge, once 
accessible, then serves to filter and interpret information about the target situation. The difference, noted by Higgins (1996) is one in which the direction of influence is from the stimulus to stored knowledge versus the direction of influence is from stored knowledge to perceptions of the stimulus. As Higgins (1996: 137) explains, "the same stimulus can function as a target and a stimulant over time..a stimulus might first function as a stimulant and activate a construct..then the stimulus might function as a target."

Finally, given that self-construals affect inferences and judgments (Fiske \& Taylor, 1991; Markus \& Wurf, 1987), in our model we predict that RSC accessibility will affect negotiators' judgments. Numerous judgment biases have been identified in negotiation research, many of which are competitive in nature (see Thompson et al., 2004, for a review). A critical question, then, is how does RSC change the nature of judgment in negotiation? Put differently, what biases are attenuated when RSC is accessible? Likewise, what biases are exacerbated when RSC is accessible? Although a discussion of all judgment biases is beyond the scope of this paper, we advance several propositions for future research. For example, RSC accessibility is expected to attenuate fixed pie biases, or "the erroneous belief that the other party's interests are directly opposed to one's own interests when, in fact, they are often not completely opposed" (Thompson et al., 2004, p. 19; Thompson \& Hastie, 1990). This bias is rooted in faulty beliefs and judgments about another party—or what Thompson et al. (2004) refer to as "other-perception biases"-and is linked to negotiators focusing on their own preferences rather than their counterparts' (Bottom \& Paese 1997; Thompson et al, 2004). However, because RSC accessibility is related to cooperative construals and a heightened awareness of others' goals and interests (Cross \& Madson, 1997; Cross et al., 2000), we expect that negotiators with RSC accessible will be less likely to assume that others' interests are completely opposed to their own at the start of negotiations, and will be more likely to gather accurate information about their partner's interests over the course of negotiations. Lending indirect support for this notion, Cross and Morris (2003) found that individuals high on RSC were better able to discern others' 
values and beliefs than were people low on RSC (see also, Greenhalgh and Gilkey, 1993). $\mathrm{RSC}$ accessibility is also expected to attenuate reactive devaluation biases, wherein concessions made are automatically devalued simply because they originate from the other party (Stillinger, Epelbaum, Keltner, \& Ross, 1990). Because RSC accessibility is related to the desire for connections and mutual aid and support (Fletcher, 1996), others' concessions are more likely to be viewed positively-as an indication that the other is willing to sacrifice their needs for the sake of the relationship.

At the same time, RSC is likely to also exacerbate certain judgment biases. For example, given their enhanced perspective taking, negotiators for whom RSC is accessible may be more vulnerable to being influenced by the other negotiator, and therefore, may be particularly susceptible to anchoring effects (Northcraft \& Neale, 1987; Tversky \& Kahneman, 1974) and/or others' communicated frames (De Drue, Emans, and van de Vliert, 1992). Likewise, when RSC is accessible and one is focused on building relationships, negotiators may be victim to certain "relational illusions." For example, they may be overly optimistic about how others feel about the relationship. This is consistent with Cross \& Morris (2003) who showed that individuals high on RSC tended to have illusions about others' feelings about the relationship. In addition, negotiators for whom RSC is accessible may unconsciously (inaccurately) assume that what is good for the other is good for the self-even if it is in fact, economically disadvantageous to the self_-in effect, a reversal of the reactive devaluation bias. In all, RSC is likely to reduce competitive judgment biases, but also may increase susceptibility to other relational biases.

Relational goals. Consistent with our discussion of relational motivation, RSC is also expected to affect negotiators' goals. Whereas economic capital has been the primary focus of negotiation research, we argue that the accumulation of relational capital is a central goal for negotiators for whom RSC is accessible. Relational capital is similar to the notion of social capital in sociology, which focuses on investments in social networks with expected returns 
(Grannoveter, 1985; Portes, 1998). However, while social capital theory typically focuses on the overall pattern of relationships among many individuals, in our model, relational capital focuses on the relational assets that accumulate within a specific dyadic negotiation relationship. We define relational capital as including assets of mutual liking, knowledge, trust, and commitment to continuing the relationship. Assets of mutual liking develop when negotiators develop a mutual attraction to each other. Assets of mutual knowledge develop when negotiators come to an understanding of each other's perspectives and needs. Assets of mutual trust develop when negotiators come to rely on each other to fulfill promises and see each other as predictable. Lastly, assets of mutual commitment develop when negotiators develop a shared desire to continue the relationship into the future. Importantly, in our view, goals for relational capital are not necessarily mutually exclusive with goals for economic capital. Yet we posit that negotiators for whom RSC is highly accessible will be likely to weigh the accumulation of relational capital as more important than the accumulation of economic capital.

Goals for accumulating relational capital are expected to be reflected in concerns that negotiators have prior to the negotiation. When RSC is accessible, negotiators are likely to be concerned with making a positive impression and avoiding making a negative impression upon the other negotiator in order to increase mutual liking and trust. Negotiators will also desire to gain personal knowledge about the other negotiator, which serves to develop mutual knowledge. And consistent with our discussion of relational motivation, RSC accessibility is expected to be associated with pre-negotiation goals of helping the other negotiators to achieve their own goals, which fosters loyalty and commitment to the relationship.

Initial offers, concessions, and relational tactical behavior. Figure 1 illustrates that RSC affects negotiators' tactical behavior in early stages of negotiations. Tactical behaviors are behaviors with a strategic focus (Weingart \& Olekalns, 2004). When negotiators have as a principal goal the accumulation of relational capital, it follows that they will engage in tactical 
behaviors that develop and enhance the connection with their counterpart and will avoid behaviors that might threaten it (Cross \& Madson, 1997; Greenhalgh, 1987). Such relational concerns will be manifested in initial offers, concession-making, and early relational tactics.

Specifically, negotiators who construe the situation through relational frames and judgments and who are focused on developing mutual liking, knowledge, trust, and commitment, will likely make initial offers that signal an interest in forming a connection with the other party, and will refrain from making offers that convey a negative impression. For example, negotiators with RSC accessible will be less likely to state very high initial demands, as this could be potentially harmful to the relationship. Likewise, the tendency to put the relationship first is likely to be reflected in individuals' willingness to make concessions early in a negotiation in order to signal their interest in building and sustaining a connection with their counterparts. This supported by Greenhalgh and Gilkey's (1993) finding that relationship-oriented negotiators are willing to make concessions with their counterpart for the sake of the future relationship, and is also consistent with research that has shown that RSC is associated with sacrificing one's own desires in order to help others with whom one is developing a connection (Cross et al., 2000; Gabriel \& Gardner, 1999). More generally, because of their longer time horizons, negotiators for whom RSC is accessible will be willing to forego short-term economic gains for the purposes of building relational capital (cf. Mannix, Tinsley, \& Bazerman, 1995).

RSC accessibility is also expected to relate to tactical behavior that serves to increase mutual liking, knowledge, trust, and mutual commitment to the relationship. First, RSC will be associated with personal information exchange-questions asked of the other negotiator as well as the willingness to self-disclose personal information. Self-disclosure is an important factor in the development of intimacy and general satisfaction in relationships, as it conveys trust and responsiveness to the other (Cross \& Morris, 2003; Laurenceau, Barrett, \& Pietromonaco, 1998). This is consistent with research that has shown that individuals with RSC accessible self-disclose more in "get-acquainted" tasks and, consequently, are viewed as more responsive 
by their counterparts (Cross et al., 2000). Likewise, research has also shown that individuals with RSC accessible elicit and remember more personal information from others (Cross \& Morris, 2003).

Second, RSC is expected to be related to relational tuning tactics, in which an individual intentionally or unintentionally matches another negotiator's nonverbal and paralinguistic behavior, tone of voice, and even speech tempo (also called social contagion, or mimicry; Thompson, 1998). This is consistent with research that has shown that RSC is associated with increased mimicry of partners' behaviors in non-negotiation contexts (Chartrand \& Bargh, 1999; Sanchez-Burks, 2002; van Baaren, Maddux, Chartrand, de Bouter, \& van Knippenberg, 2003). For example, Chartrand \& Bargh (1999) showed that individuals who were high on perspective taking (i.e., being attuned to the behavior of one's counterpart, which is related to relational cognition, as discussed previously) were more likely to engage in behavioral mimicry. Likewise, Sanchez-Burkes (2002) showed that women, who we have argued are more likely to have chronic RSC accessibility, were more likely to engage in behavioral mimicry than European Americans. More generally, negotiators for whom RSC is accessible will make efforts to be insync (Blount \& Janicik, 2003) in their personal styles and mannerisms. Being in-sync facilitates the smoothness of interactions and fosters liking and rapport (Chartrand \& Bargh, 1999), which are key concerns among those with RSC accessible.

Finally, just as negotiators for whom RSC is accessible will likely engage in behaviors that help to develop and affirm a connection with the other, they will be unlikely to use tactics that could potentially damage the relationship (cf. Greenhalgh \& Gilkey, 1993). For example, they will likely avoid self-enhancement, such as bragging about themselves or emphasizing other options that they have as alternatives (i.e., their BATNAS). Rather, RSC will lead to a focus on relationship enhancement-expressions of agreement, empathy with another's position, and enthusiasm about the interaction. Negotiators for whom RSC is accessible will 
also be less likely to use distributive tactics, such as putdowns, threats and warnings, which imply separation from the ongoing relationship.

Although there is no direct evidence for these notions, research on negotiations with close friends and romantic partners—conditions that we argue increase temporary accessibility of RSC—offers some support for these propositions. Generally speaking, close ties among negotiators have been found to produce more concession-making, less competition, and more cooperative tactics (Greenhalgh \& Chapman, 1998; Halpern, 1992; Schoeninger \& Wood, 1969; Thompson \& DeHarpport, 1998). For example, Fry et al. (1983) found that dating couples used fewer pressure tactics and were less willing to push hard for their own interests than were mixed-sex stranger couples. Likewise, Polzer, Neale and Glenn (1993) argued that negotiations among friends often involve a "politeness ritual" wherein negotiators want to appear modest, polite, and unselfish (Valley, Neale, \& Mannix, 1995). Our model begins to provide an understanding for why these tactics might be used, showing how the relational self and its associated cognitive, motivational, and emotional processes may mediate the effects of close ties.

We have thus far discussed the initial tactical behaviors of negotiators with RSC accessible, who we argue strategically attempt to accumulate relational capital. Negotiation, however, is by definition a dyadic experience, in which the behavior of one's counterpart invariably affects one's own later tactics and outcomes. We posit that both the strength of RSC accessibility in dyads as well as the congruency of RSC between negotiators are important determinants of later relational dynamics and negotiation outcomes. Next, we first explore the impact of the strength of RSC accessibility in dyads on relational dynamics and outcomes. In this discussion, we assume that both members of a negotiating dyad have similar levels of RSC. We then examine the effect of RSC incongruency in dyads, highlighting likely relational dynamics and consequences when negotiators have dissimilar levels of RSC accessibility. RSC Accessibility Strength and Negotiation Outcomes 
A central prediction is that RSC will have a curvilinear effect on negotiation outcomes with negotiators who have moderate RSC accessibility strength attaining the most overall capital-i.e., both high relational and high economic capital—as compared to negotiators with low or high RSC accessibility. We elaborate on these predictions below, discussing unique relational dynamics that are likely to transpire among negotiators with high, moderate, and low RSC accessibility, and how they lead to varying levels of economic and relational capital.

\section{Figure 2}

\section{RSC Dynamics in Negotiation}

\begin{tabular}{|c|c|c|}
\hline \multirow[b]{2}{*}{$\begin{array}{c}\text { RSC ACCESSIBILITY } \\
\text { NEGOTIATIOR } 1\end{array}$} & $\begin{array}{l}\text { RSC Incongruency: } \\
\text { Relational Distancing }\end{array}$ & $\begin{array}{l}\text { RSC Congruency: } \\
\text { Relational Satisficing }\end{array}$ \\
\hline & \multicolumn{2}{|c|}{$\begin{array}{l}\text { RSC Congruency: } \\
\text { Relational Integrating }\end{array}$} \\
\hline \multirow[t]{3}{*}{ Low } & $\begin{array}{l}\text { RSC Congruency: } \\
\text { Arelational Trading }\end{array}$ & $\begin{array}{l}\text { RSC Incongruency: } \\
\text { Relational Distancing }\end{array}$ \\
\hline & Low & High \\
\hline & \multicolumn{2}{|c|}{$\begin{array}{l}\text { RSC ACCESSIBILITY } \\
\text { NEGOTIATOR } 2\end{array}$} \\
\hline
\end{tabular}

High RSC Accessibility and Negotiation Outcomes. First, dyads in which both parties have very high RSC accessibility are predicted to experience what we call a Relational Satisficing Dynamic, as shown in Figure 2. These negotiators will likely engage in relational tactical behaviors, and they will tend to experience positive emotions given that the relational self is being affirmed and relational capital (i.e., mutual liking, knowledge, trust, and 
commitment) is developing. These positive emotions, in turn, are expected to strengthen RSC accessibility and further enhance the negotiators' use of relational tactics (e.g., concessions, relational tuning). Due to the cyclical processes of positive affect and highly concessionary and cooperative behavior, we expect that these dyads will build considerable relational capital by the end of the negotiation. However, we note that these dyads may not achieve very high individual or joint economic capital, at least in the short run. Negotiators with very high RSC accessibility are expected to be intensely focused on the relationship, and thus relational issues are expected to loom much larger than economic returns (cf. Greenhalgh \& Gilkey, 1993). Put differently, although highly concessionary and cooperative behaviors are useful for the development of relational capital, they are not necessarily effective at creating value-or expanding the pie of resources. Negotiators with very high RSC accessibility will also be averse to appearing selfish and focusing on their own interests, and thus, are unlikely to claim value. For these reasons, we argue that these dyads may not achieve very high individual or joint economic capital.

Although future research needs to substantiate these notions, there is some indirect support for the Relational Satisficing dynamic in literature on negotiations between close friends or romantic partners, conditions we have argued temporarily activate strong RSC accessibility among negotiators. For example, Fry et al. (1983) found that couples achieved considerably lower joint economic gain than strangers, and consistent with the dynamic discussed above, they argued that low joint gain was due to concerns for the development and protection of the relationship. The dynamic of Relational Satisficing is also consistent with research by Thompson et al. (1996) which found that negotiations among close friends produced fewer integrative solutions than negotiations among strangers, possibly because close friends were focused exclusively on maintaining solidarity and agreement on non-task issues and avoiding disagreement on task-related issues (see also Schoeninger \& Wood, 1969). Finally, this dynamic is consistent with research by Tenbrunsel, Wade-Benzoni, Moag, \& Bazerman (1999), 
who found that strong ties among negotiators can produce economically subobtimal agreements. We posit that it is possible to understand many of the above findings, at least in part, through a common mechanism, namely the strength of RSC accessibility and its associated processes.

Moderate RSC Accessibility and Negotiation Outcomes. Next, we examine the case in which RSC accessibility is moderately strong among negotiators. As seen in Figure 2, negotiators who have moderate RSC accessibility are expected to experience what we call a Relational Integrating Dynamic. As in dyads with high RSC accessibility, both negotiators in this condition will likely engage in relational tactics and will experience positive emotions as their relational selves are affirmed and relational capital develops. Such processes will engender later relational tactics that serve to further strengthen the relational capital they have accumulated. However, because these individuals do not define themselves as strongly in terms of relationships, they are likely be more mindful of other outcomes of the negotiationnamely the economic capital that can be achieved. In other words, as compared to high RSC accessibility dyads, these negotiators are unlikely to focus exclusively on the relationship, and will begin identifying ways to create economic value both for themselves and the dyad in later stages of the negotiation. In keeping with our RSC perspective, the creation of economic value in these dyads will likely have a distinctly relational character. For example, with their enhanced relational knowledge and understanding of each other's interests, these dyads will be in a good position to identify compatible issues, to recognize possible trade-offs, and to suggest ways in which both can benefit. Likewise, with their temporally embedded construal of the negotiation, they will be able to create mutually-satisfying trade-offs that capitalizes on different time perspectives (i.e., l'll give you this now if you will give me this later; Mnookin, Peppet, \& Tulumello, 2000). We note, however, that in addition to creating value, negotiators in these dyads are expected to be more concerned with their own outcomes, and thus, will be more likely to claim economic value for themselves as well. Due to the cyclical processes of relational 
tactics combined with value creation and claiming, we expect that these dyads will build considerable individual and joint relational capital and economic capital.

Low RSC Accessibility and Negotiation Outcomes. Lastly, we consider the case when negotiators have low RSC accessibility, arguing that it will result in what we refer to as an Arelational Trading Dynamic. In this dyadic composition, both negotiators are likely to engage in arelational tactical behavior. That is, rather than engaging in relational behaviors that lead to the development of relational capital in later parts of the negotiation, they will focus instead primarily on material or economic aspects of the interaction and will engage largely in taskoriented exchange_-for example, exchanging multiple proposals and offers in a rather nonrelational manner, or discussing underlying interests regarding the material aspects of the negotiation. Such heuristic trial and error (Pruitt, 1983; Tutzauer \& Roloff, 1988) can help these negotiators create value, and consequently, we expect that congruency in low RSC accessibility can lead to high individual and joint economic capital. This prediction is supported in part by Olekalns \& Smith (2003), who found that individualistically oriented dyads achieved high joint value by engaging in the exchange of multiple issue offers. Pinkley \& Northcraft (1994) also found that task frames relate to high joint and individual profit. We would note, however, that although the Arelational Trading dynamic is generally expected to produce high economic capital, it is entirely possible that if in the course of interacting, negotiators shift from a taskoriented focus to a competitive focus, the dyad will achieve lower individual and joint gain. Moreover, although dyads that share low RSC accessibility are generally likely to develop economic capital, it is unlikely that they will develop as much relational capital, at least in the short run, as other dyadic compositions described above, given that they are not focused on the achievement of relational goals. In other words, because low RSC accessibility negotiators will not be as focused on the relational aspects of their interactions, they will be less likely to develop outcomes that include relational components. This is consistent with Pinkley \& Northcraft (1994), who argued that task-focused disputants do not tend to have relationship 
maintenance issues in their final settlements. More generally, effects for negotiators with low RSC accessibility are expected to be the mirror image of those with high RSC accessibility: while low RSC negotiators are expected to accumulate relatively high individual and joint economic capital and low relational capital, high RSC negotiators are expected to accumulate relatively low economic capital and high relational capital.

\section{RSC Congruency versus Incongruency}

In the discussion above, we assumed that both negotiators in a dyad shared similar levels of RSC accessibility. Yet often this may not be the case, raising the natural question: What relational dynamics and outcomes characterize such dyads? A key prediction of our model is that dyadic incongruency of RSC will relate to lower joint economic and relational capital than dyadic congruency, regardless of the negotiators' strength of RSC accessibility. There is abundant evidence that incongruency in goals (e.g., Kristof-Brown \& Stevens, 2001), values (e.g., Adkins, Russell, \& Werbel, 1994), and/or personality (e.g. Smith, 1998), is related to higher conflict (Jehn, Chadwick, \& Thatcher, 1997), lower communication quality (Gelfand, Radhakrishnan, \& Kuhn, 1996), and more negative perceptions of interaction partners (Adkins, et al. 1994). Incongruency is also related to lower trust, satisfaction, and commitment (KristofBrown, Jansen, \& Colbert, 2002; Meglino et al., 1989). By contrast, congruency is thought to be beneficial because it increases attraction and liking (Byrne, 1961; Newcomb, 1956; Tsui, Egan \& O'Reilly, 1992), contributes to individuals' positive social identity and self-esteem (Ashforth \& Mael, 1989; Tajfel \& Turner, 1986), and helps partners coordinate their behavior according to a common set of expectations (Barsade, Ward, Turner \& Sonnenfeld, 2000; Triandis, 1959; Thompson \& DeHarpport, 1998).

Building on this literature, we expect that dyads who have incongruent levels of RSC accessibility -in which RSC is asymmetric between negotiators-will have lower perceptions of similarity, experience more negative emotions, have difficulty coordinating their interactions, and have lower trust and commitment, all of which is likely to thwart their ability to understand each 
other's interests and make mutual trade-offs. Our previous discussion of RSC accessibility also helps to understand further the negative negotiation dynamics that are expected to be associated with RSC incongruency. For example, persons with strong RSC accessibility experience distress and negative affects when their efforts to develop a connection are thwarted (Cross \& Madson, 1997), resulting in behaviors ranging from relational aggression to withdrawal from the interaction (Cross \& Madson, 1997). Regardless of whether aggression or withdrawal is chosen as a response, we argue that the ultimate result for both is the same: Since neither of these behaviors leads to the creation of value, we predict that compared to congruent dyads, dyads with RSC incongruency will ultimately achieve lower individual and joint economic capital, and will also experience a further distancing of the relationship, leading to lower relational capital. In addition, these dyads are likely to experience more unequal negotiation outcomes, with individuals high on RSC likely achieving lower outcomes than those low on RSC. We refer to this phenomenon as a Relational Distancing dynamic, depicted in Figure 2.

Although there is little research that has investigated the impact of negotiator congruency versus incongruency, indirect support for this proposition can be found in the negotiation literature. For example, Thompson \& DeHarpport (1998) found that friends engaging in problem-solving tasks who were dissimilar in communal orientation obtained lower settlement outcomes compared to friends who both had either very high or very low communal orientation. Our notion of Relational Distancing is also consistent with research by McGinn and Keros (2002), who found that in asymmetric dyads in which one party cooperated and the other was non-responsive, the cooperator reacted in one of two ways: They either became angry and lashed out at the other party or they broke off from the interaction and sacrificed agreement. Likewise, research has shown that prosocial individuals respond very competitively when dealing with non-cooperative individuals (Kelley \& Stahelski, 1970; Van Lange, 1999). Finally, the Relational Distancing dynamic is also indirectly supported by research on gender, which we have previously linked to RSC. In situations where cooperation is expected but not forthcoming, 
women have been found to react with anger and aggression (Mikolic, Parker, \& Pruitt, 1997; Rapoport \& Chammah, 1965; Swap \& Rubin, 1983; Tedeschi, Schlenker, \& Bonoma, 1973).

\section{Post Settlement Compliance and Future Negotiations}

Negotiations are not always discrete, one-time events (Mannix et al., 1995), but rather require compliance with agreements and the possibility of future interaction. Thus, even if an agreement is reached, it may fall through because one or both parties ultimately reneg on the terms of their agreement (Barry \& Oliver, 1996). We predict that the relational dynamics that transpire during the negotiation will affect negotiators' willingness to comply with agreements as well as their interest in engaging in future negotiations. For example, dyads in which RSC is incongruent are expected to be less willing to comply with agreements and to engage in future negotiations with their counterparts relative to congruent dyads. As discussed, incongruent dyads are expected to have experienced more negative emotions, have had more difficulty coordinating their action and developing trust, and to have achieved lower joint economic and relational capital, all of which should result in less commitment to agreements that have been reached and less interest in engaging in future negotiations. This is consistent with research that has shown that incongruency in groups is related to lower commitment, motivation, and turnover (see Kristoff-Brown, 1996, for a review). It is also consistent with research by Allred et al. (1997), which found that negotiators who experience negative emotions during negotiations have less of a desire to interact with their partners in the future (see also O'Connor \& Arnold, 2001).

In dyads in which RSC is congruent, we expect that negotiators' willingness to comply with agreements and engage in future negotiations will be contingent on the amount of economic and relational capital achieved as well as the strength of RSC accessibility in the dyad. Dyads with high RSC accessibility are expected to be more satisfied and willing to comply with agreements to the extent they have achieved high relational capital, even if they have not achieved significant economic capital. If such negotiators are in markets where 
opportunity costs and uncertainty about exploitation with other partners are high, this accumulation of relational capital early on may ultimately lead to considerable economic gain over the long run (cf. Tenbrunsel et al., 1999). By contrast, dyads with low RSC accessibility will be more satisfied and willing to comply with agreements to the extent that they have achieved high economic capital, regardless of the relational capital that has initially developed. Indeed, as noted by an anonymous reviewer, if there is an opportunity for on-going transactions, high economic gain may ultimately make these negotiators more committed to maintaining their connection in order to reap additional economic benefits (and possibly even strengthen RSC in these dyads), and ultimately, they may also gain considerable relational capital over the long run.

\section{Discussion}

Negotiation research, while thriving, has historically been criticized as having an arelational bias_-focusing primarily on autonomy, competition, and rationality rather than interdependence, cooperation, and relationality. Yet with few exceptions, little conceptual work has been done to specify the precise nature of the construct of relationality or how it affects negotiators' psychological states, tactics, and outcomes.

We sought to move beyond abstract critiques of arelationality and to provide a concrete agenda for future research. Drawing on literature on the social psychology of the relational self, we advanced a more comprehensive model of relationality in negotiation. We have shown that in addition to certain individual and group differences in chronic accessibility of RSC, features of the negotiation context can increase the temporary accessibility of RSC as well as inhibit is use. We delineated how RSC is linked to negotiators' psychological states (frames, judgments, and goals) as well as early tactical behavior, and we detailed unique relational dynamics—Relational Satisfying, Relational Integrating, Arelational Trading, and Relational Distancing-that can occur at the negotiation table based on the dyadic composition of RSC. Our account clearly shows 
that different forms of negotiating relationally bring distinct benefits and costs to the negotiation table which need to be balanced in the pursuit of relational and economic capital.

Implications for theory and research. Our model of RSC in negotiation has the potential to expand negotiation theory by opening up new ways to look at previous research and by illustrating linkages across diverse areas in the field. For example, we have begun to show how disparate areas such as negotiations with close others, gender differences, and differences across communication media can be seen, at least in part, through a common lens-the relational self. Our model also expands negotiation theory by offering new avenues for research on age-old phenomena. For example, we expand the focus on economic capital, which is prioritized in the field, to also include a focus on relational capital. More generally, our model highlights the critical need to develop and incorporate good measures of relational constructs into negotiation research. Fortunately, there are a number of existing measures of RSC that can be readily incorporated into negotiation research (see Aron et al., 1992; Cross et al., 2000; Y. Kashima et al., 1995; E. Kashima \& Hardie, 2000), and the creation of new priming measures of the relational self would prove useful in this regard as well (cf. Trafimow, Triandis, \& Goto, 1991, for examples of priming the collective self). Yet other relational constructs that we advanced that are specific to negotiation need further research attention. For example, our model illustrates the need to assign value to the dimensions of relational capital that we have articulated (mutual liking, mutual knowledge, mutual respect, and mutual commitment) in experimental and field studies. Likewise, relational aggression-a construct that arguably represents a "downside" of RSC—-should also be the focus of measurement in negotiation.

More generally, our discussion highlights the importance of re-examining existing negotiation constructs and theories through an RSC lens. Future research will benefit, for example, from examining the dynamics of power in negotiation vis-à-vis RSC. Although high power has been generally linked to self-interested behavior (e.g., Kipnis, 1972) and judgmental inaccuracy in conflicts (Ebenbach \& Keltner, 1998), power in negotiation is likely to be used in a 
more socially responsive way when RSC is accessible (cf. Chen et al., 2001). This is consistent with research by Chen et al. (2001), which found that individuals in positions of power who had a "communal orientation" were more responsive to the needs of others. Accordingly, it would be interesting to examine how RSC moderates the effect of high power in negotiations. We would predict, for example, that having a high BATNA would be more likely to influence tactics among negotiators with low RSC accessibility than negotiators with high RSC accessibility. The latter may be more reluctant to mentioning their BATNAs as leverage, as this could thwart the development of relational capital. Likewise, a relational perspective on cognitive biases in negotiation might also prove fruitful. Earlier we discussed how RSC might attenuate fixed pie and reactive devaluation biases, but an equally important question is whether there are unique biases that have heretofore not surfaced that might occur as a result of RSC accessibility. In addition, as noted above, our model illustrates the importance of looking not only at individual-level RSC, but congruency in RSC at the dyadic level in negotiation research. Although there have been some scholars who have investigated congruency in negotiation (e.g., McGinn \& Keros, 2002; Pinkley \& Northcraft, 1994; Thompson \& DeHarrport, 1998), many models of negotiation have focused on the individual level of analysis without regard for the nature of the dyad. For example, the dual concern model (Pruitt \& Rubin, 1986), one of the most widely discussed models of conflict management, focuses upon a single individual's approach to conflict management. Our analysis shows the necessity of looking not only at an individuals' strength of RSC accessibility but also the congruency that exists (or lack thereof) in order to better predict dynamics and outcomes of negotiations. Moreover, future research would benefit from examining factors that moderate the negative effect of RSC incongruity in negotiation. For example, in conditions where negotiators share superordinate goals, dyads may be able to overcome the potentially negative effects of incongruity (Hunger and Stern, 1976; Sherif \& Sherif, 1969). Situations in which both negotiators have few alternative options 
(e.g., each has a low BATNA) may also mitigate negative effects of incongruency, as negotiators will be more motivated to work together to find a good solution.

The theory also provides an alternative way to understand individual differences in negotiation. We have argued that individual differences are dynamic, and do not necessarily translate into behavior if they are not relevant to the context. For example, although women are generally higher on RSC than men, we argued that RSC will be inhibited under certain conditions, which should attenuate gender differences. Our focus shifts the discussion of gender differences in negotiation from stable traits, which are typically used to differentiate males and females, to social cognition—self-schemas that are dynamically accessible and are context-dependent. Future research may benefit from examining gender and other individual difference variables using a social cognition perspective (cf. Morris \& Gelfand, 2004).

Finally, although we have been necessarily selective in our discussion of the potential that RSC has for negotiation research, an RSC perspective will also be useful in the field of OB more generally. Similar to the negotiation literature, the OB literature has been criticized as having an arelational focus (Fletcher \& Jaques, 1999; see also Barry \& Crant, 2000; Bradbury \& Bergmann, 2000). We believe that an RSC perspective would benefit a wide range of OB phenomena-including emotional labor, leadership, organizational citizenship behaviors, and organizational culture. For example, RSC may be related to emotional labor, or the strain that people experience in roles where there is a constant requirement to meet the needs of and be responsive to others (e.g., service providers; Gross, 1998; Hochschild, 1983; Rafaeli, 1993). People with RSC accessible may generally experience less strain than those with low RSC accessibility because they are more genuinely interested in developing relationships (cf., Pugh, 2002). At the same time, conflictual relationships with customers or clients may be the source of more stress among those with RSC accessible. RSC is also relevant for the study of organizational citizenship behaviors (Organ, 1988), as individuals with RSC accessible may be more willing to engage in interpersonally-oriented helping behaviors (Lee \& Allen, 2002). RSC 
is also relevant for leadership in organizations. Research and theory have begun to investigate the link between leadership and followers' self-concepts (Lord \& Brown, 2004), and there is some evidence that a relational connection with one's leader is important for follower empowerment (Kark, Shamir \& Chen, 2003), and effect that we would expect would be pronounced for those with RSC accessible. On the flipside, it would also be interesting to examine the impact of RSC accessibility on specific behaviors of leaders (e.g., transformational versus transactional approaches). Lastly, RSC may be implicated in macro phenomena such as organizational culture. For example, if the founder of a company has high chronic RSC accessibility, we might expect that the h/she may develop a relational culture which emphasizes cooperation, interpersonal sensitivity, and mutual empowerment.

Implications for practice. Our model begins to identify when and how relational issues become manifest in negotiation, and has the potential to enhance negotiation training. For example, the model of RSC and negotiation delineates conditions that are expected to either accentuate (e.g., negotiations with friends) or attenuate (e.g., negotiations over lean media) RSC in negotiations. Just as negotiators can be taught strategies for problem-solving, we believe that they can also be taught to be aware of the costs and benefits of various relational dynamics in negotiation. For instance, trainers can highlight the conditions that may foster a Relational Satisficing dynamic among negotiators, and teach strategies for developing economic capital in addition to relational capital. Likewise, they can highlight the impact of RSC incongruency in dyads and help negotiators to develop strategies to overcome these negative dynamics. More generally, we move beyond recommendations to "separate the people from the problem" (Fisher, Ury, \& Patton, 1991, p. 17) and instead, delineate specific dynamics that can occur when people are focused on relationality in negotiation. By including relational capital as a goal of negotiations that is on par with attaining economic capital, we also emphasize the importance of relationship maintenance as a legitimate goal about which negotiators should be concerned. 
Concluding remarks. Negotiation theory and research have historically been criticized as having an arelational bias. Our model, grounded in the nature of the self, offers an enriched relational perspective on negotiation. It helps us to understand diverse phenomena in negotiation, raises new questions for empirical investigation, and ultimately illuminates the complex dynamics of what it means to negotiate relationally. 


\section{References}

Adkins, C. L., Russell, C. J., Werbel, J. D. 1994. Judgments of fit in the selection process: The role of work value congruence. Personnel Psychology, 47: 605-623.

Allred, K. G., Mallozzi, J. S., Matsui, F., \& Raia, C. P. 1997. The influence of anger and compassion on negotiation performance. Organizational Behavior and Human Decision Processes, 70: 175-187.

Andersen, S. M., \& Chen, S. 2002. The relational self: An interpersonal social-cognitive theory. Psychological Review, 109: 619-645.

Aron, A., Aron, E., \& Smollman, D. 1992. Inclusion of others in the self scale and the structure of interpersonal closeness. Journal of Personality and Social Psychology, 63: 596-612.

Ashforth, B. E., \& Mael, F. 1989. Social identity theory and the organization. Academy of Management Review, 14: 20-39.

Bakan, D. 1966. The duality of human existence. Boston, MA: Beacon Press.

Baldwin. M. W. 1992. Relational schemas and the processing of social information. Psychological Bulletin, 3: 461-484.

Bargh, J., Bond, R. N., Lomabardi, W. J., \& Tota, M. E. 1986. The additive nature of chronic and temporary sources of construct accessibility. Journal of Personality and Social Psychology, 50: 869-878.

Barley, S. R. 1991. Contextualizing conflict: Notes on the anthropology of disputes and negotiations. In M.H. Bazerman, R. J. Lewicki, \& B.H. Sheppard, (Eds.) Research on Negotiation in Organizations (Vol. 3). Greenwich, CT: JAI Press.

Barry, B., \& Crant, M .J. 2000. Dyadic communication relationships in organizations: An attribution expectancy approach. Organization Science, 11: 648-664.

Barry, B., \& Friedman, R. A. 1998. Bargainer characteristics in distributive and integrative negotiation. Journal of Personality and Social Psychology, 74: 345-359.

Barry, B. \& Oliver, R. L. 1996. Affect in dyadic negotiation: A model and propositions: Organizational Behavior and Human Decision Processes, 67: 127-143.

Barsade, S.G., Ward, A.J., Turner, J.D.F., \& Sonnenfeld, J.A. 2000. To your heart's content: A model of affective diversity in top management teams. Administrative Science Quarterly, 45: 802-836.

Benton, A. A., \& Druckman, D. 1973. Salient solutions and the bargaining behavior of

representatives and nonrepresentatives. International Journal of Group Tensions, 3: 28-39. Blount, S. \& Janicik, G. 2003. Getting and staying in-pace: the in-synch preference and its implications for work groups. In M. A. Neale, E. Mannix, \& H. Sondak (Eds). Research on managing groups and teams in organizations, Vol. 4, Stanford, CT: JAI Press. Bottom, W. P., \& Paese, P. 1997. False consensus, stereotypic cues, and the Perception of integrative potential in negotiation. Journal of Applied Social Psychology, 27: 1919-1940.

Bradbury, H., \& Bergmann, B.M. 2000. Relationality in organizational research: Exploring the space between. Organization Science, 11: 551-164.

Bruner, J. S. 1957. On perceptual readiness. Psychological Review, 64: 123-152.

Brewer, M. B., \& Gardner, W. 1996. Who is this "we"? Levels of collective identity and self representations. Journal of Personality and Social Psychology, 71: 83-93.

Byrne, D. 1961. Interpersonal attraction and attitude similarity. Journal of Abnormal and Social Psychology, 62: 713-715.

Carver, C. S., \& Scheier, M. F. 1981. Attention and self-regulations: A control theory approach to human behavior. New York: Springer-Verlag.

Chartrand, T. L, \& Bargh, J. A. 1999. The chameleon effect. The perception-behavior link and social interaction. Journal of Personality and Social Psychology, 76: 893-910. 
Chen, S. 2001. The role of theories in mental representations and their use in social perception: A theory-based approach to significant-other representations and transference. In G. B. Moskowitz (Ed.) Cognitive social psychology: The Princeton Symposium on the Legacy and Future of Social Cognition (pp. 125-142). Mahwah, NJ, US: Lawrence Erlbaum Associates.

Chen, S. 2003. Psychological-state theories about significant others: Implications for the content and structure of significant-other representations. Personality and Social Psychology Bulletin, 29: 1285-1302

Chen, S., Lee-Chai, A. Y. \& Bargh, J. A. 2001. Relationship orientation as a moderator of the effects of social power. Journal of Personality and Social Psychology, 80: 173-187.

Choi, S. C., Kim, U., \& Choi, S. H. 1993. Indigenous analysis of collective representations: A Korean perspective. In U. Kim and J. W. Berry (Eds.) Indigenous Psychologies: Research and experience in cultural context, Newbury Park, CA: Sage.

Clancy, S. M., \& Dollinger, S. J. 1993. Photographic depictions of the self: Gender and age differences in social connectedness. Sex Roles, 29: 477-495.

Croson, R. 1999. Look at me when you say that: An electronic negotiation simulation.

Simulation and Gaming, 30: 23-37.

Cross, S.E., Bacon, P.L., \& Morris, M.L. 2000. The relational-interdependent self-construal and relationships. Journal of Personality \& Social Psychology, 78: 191-208.

Cross, S. E., \& Madson, L. 1997. Models of the self: Self-construals and gender. Psychological Bulletin, 122: 5-37.

Cross, S. E., \& Morris, M. L. 2003. Getting to know you: The relational self-construal, relational cognition, and well-being. Personality and Social Psychology Bulletin, 29: 512-523.

Cross. S. E., Morris, M. L., \& Gore, J. S. 2002. Thinking about oneself and others: The relational-interdependent self-construal and social cognition. Journal of Personality and Social Psychology, 3: 399-418.

De dreu, C. K.W., Emans, B. J. M., \& van de Vliert, E. 1992. The influence of own cognitive and other's communicated gain or loss frame on negotiation behavior. International Journal of Conflict Management, 3: 115-132.

Devine, P. 1989. Stereotypes and prejudice: Their automatic and controlled components. Journal of Personality and Social Psychology, 56: 680-690.

Davis, M. Conklin, L., Smith, A., \& Luce, C. 1996. Effect of perspective taking on the cognitive representation of persons: A merging of self and other. Journal of Personality \& Social Psychology, 70: 713-726.

De Dreu, C.K.W., \& Carnevale, P. J. 2003. Motivational bases of information processing and strategy in negotiation and social conflict. In M.P. Zanna (Ed.), Advances in Experimental Social Psychology (vol. 35). New York: Academic Press

De Dreu, C.K.W., Weingart, L.R., \& Kwon, S. 2000. Influence of social motives on integrative negotiation: A meta-analytical review and test of two theories. Journal of Personality and Social Psychology, 78: 889-905.

Diekmann, K. A. 1997. Implicit justifications" and self-serving group allocations. Journal of Organizational Behavior, 18: 3-16.

Ebenbach, D.H., \& Keltner, D. 1998. Power, emotion, and judgmental accuracy in social conflict: Motivating the cognitive miser. Basic and Applied Social Psychology, 20: 7-21.

Fisher, R., Ury, W., \& Patton, B. 1991. Getting to yes: Negotiating agreement without giving in $\left(2^{\text {nd }}\right.$ ed.). New York: Penguin.

Fiske, S. T., \& Taylor, S. E. 1991. Social Cognition (2 ${ }^{\text {nd }}$ ed.). New York: McGraw-Hill.

Fletcher, J. K. 1996. Relational theory in the workplace. Work in Progress Series, Paper \#77, Stone Center, The Wellesley Centers for Women, Wellesley College, Wellesley, MA. 
Fletcher, J. K., \& Jacques, R. 1999. Relational practice: An emerging stream of theory and its significance for organizational studies. Working Paper, No. 2. Center for Gender in Organizations, Simmons Graduate School of Management, Boston, MA.

Fry, W. R., Firestone, I. J., \& Williams, D. 1983. Negotiation process and outcome of stranger dyads and dating couples: Do lovers lose? Basic and Applied Social Psychology, 4: 116.

Gabriel, S., \& Gardner, W. L. 1999. Are there "his" and "hers" types of interdependence? The implications of gender differences in collective versus relational interdependence for affect, behavior, and cognition. Journal of Personality and Social Psychology, 77: 642-655.

Galinsky, A. D. \& Moskowitz, G. B. 2000. Perspective-taking: Decreasing stereotype expression, stereotype accessibility, and in-group favoritism. Journal of Personality and Social Psychology, 78: 708-724.

Gardner, W. L, Gabriel, S., \& Hochschild, L. 2002. When you and I are "we," you are not threatening: The role of self-expansion in social comparison. Journal of Personality and Social Psychology, 82: 239-251.

Gelfand, M., Kuhn, M., \& Radhakrishnan, P. 1996. The effects of value differences on social interaction processes and job outcomes in organizations: Implications for managing diversity. In M. Ruderman, M. Hughes-James, \& S. E. Jackson (Eds.) Selected research on team diversity (pp. 53-71). Greensboro: Center for Creative Leadership/APA.

Gelfand, M., \& Realo, A. 1999. Individualism-collectivism and accountability in intergroup negotiations. Journal of Applied Psychology, 84: 721-736.

Gilligan, C. 1982. In a different voice: Psychological theory and women's development. Cambridge, MA: Harvard University Press.

Gittell, J. H. 2003. The southwest airlines way: Using the power of relationships to achieve higher performance. New York: McGraw-Hill.

Granovetter, M. 1985. Economic and social structure: the problem of embeddedness. American Journal of Sociology, 91: 481-510.

Gray, B. 1994. The gender-based foundations of negotiation theory. In R. J., Lewicki, B. H. Sheppard \& R. Bies (Eds.), Research on negotiation in organizations (Vol. 4): 3-36. Greenwich, CT: JAI Press.

Greenhalgh, L. 1987. Relationships in negotiation. Negotiation Journal, 3: 235-243.

Greenhalgh, L. \& Chapman, D. I. 1995. Joint decision-making: The inseparability of relationships and negotiation. In R. M. Kramer \& D. M. Messick (Eds.) Negotiation as a social process (pp. 166-185). Thousand Oaks, CA: Sage.

Greenhalgh, L. \& Chapman, D. I. 1998. Negotiator relationships: Construct measurement,

And demonstration of their impact on processes and outcomes of negotiation. Group Decision and Negotiation, 7: 465-489.

Greenhalgh, L., \& Gilkey, R. W. 1993. The effect of relationship orientation on negotiators' cognitions and tactics. Group Decision and Negotiation, 2: 167-186.

Gross, J. 1998. The emerging field of emotion regulation: An integrative review. Review of General Psychology, 2: 271-299.

Gruder, C. L. 1971. Relationship with opponent and partner in mixed-motive bargaining. Journal of Conflict Resolution, 15: 403-416.

Halpern, J. 1992. The effect of friendship on decisions: An experimental study of personal transactions. Best Paper Proceedings, Academy of Management Conference, Las Vegas, Nevada.

Higgins, E. T. 1987. Self-discrepancy: A theory relating self and affect. Psychological Review, 94: 319-340.

Higgins, E. T. 1989. Knowledge accessibility and activation: Subjectivity and suffering from unconscious sources. In J. S. Uleman \& J. A. Bargh (Eds.) Unintended thought: The limts of awareness, intention, and control (pp. 75-123). New York: Guilford. 
Higgins, E. T. 1996. Knowledge activation: Accessibility, applicability and salience. In E. T. Higgins \& A. W. Kruglanski (Eds.), Social psychology: Handbook of basic principles (pp. 133-168). New York: Guilford Press.

Higgins, E. T., \& Brendl, M. 1995. Accessibility and applicability: Some 'activation rules' influencing judgment. Journal of Experimental Social Psychololgy, 31: 218-243.

Higgins, E. T., \& King, G. 1981. Accessibility of social constructs: Information processing consequences of individual and contextual variability. In N. Cantor \& J. Kihlstrom (Eds.) Personality, cognition, and social interaction (pp. 69-121). NJ: Erlbaum.

Higgins, E. T., Shah, J., \& Friedman, R. 1997. Emotional responses to goal attainment: Strength of regulatory focus as a moderator. Journal of Personality and Social Psychology, 72: 515-525.

Hochschild, A.R. 1983. The managed heart: Commercialization of human feeling. Berkeley: University of California Press.

Hunger, J.D., \& Stern, L.W. 1976. An assessment of the functionality of the superordinate goal in reducing conflict. Academy of Management Journal, 19: 591-605.

Jehn, K. A., Chadwick, C., \& Thatcher, S. M. B. 1997. To agree or not to agree: The effects of value congruence, individual demographic dissimilarity, and conflict on workgroup outcomes. International Journal of Conflict Management, 8: 287-305.

Jordan, J. V. 1997. A relational perspective for understanding women's development. In Women's growth in diversity: More writings from the Stone Center (pp. 9-24). New York: The Guilford Press.

Kark, R., Shamir, B., \& Chen, G. 2003. The two faces of transformational leadership: Empowerment and dependency. Journal of Applied Psychology, 88: 246-255.

Kashima, E., \& Hardie, E. A. 2000. The development and validation of the relational, individual, and collective self-aspects (RIC) scale. Asian Journal of Social Psychology, 3: 19-58.

Kashima, Y., Yamaguchi, S., Kim, U., Choi, S., Gelfand, M. J., \& Yuki, M. 1995. Culture, gender, and self: A perspective from individualism-collectivism research. Journal of Personality and Social Psychology, 69: 935-937.

Kelley, H. H., \& Stahelski, A. J. 1970. Social interaction basis of cooperators' and competitors' beliefs about others. Journal of Personality and Social Psychology, 16: 66-91.

Kihlstrom J. F., \& Cantor, N. 1984. Mental representations of the self. In L. Berkowitz (Ed.), Advances in experimental social psychology (vol. 17): 2-48. New York: Academic Press.

Kihlstrom, J. F. \& Klein, S. B., 1994. The self as a knowledge structure. In R. S. Wyer \& T. K. Srull (Eds.) Handbook of Social Cognition (Vol 1, pp. 153-208). NJ: Lawrence Erlbaum.

King, W.C., \& Hinson, T.D. 1994. The influence of sex and equity sensitivity on relationship preferences, assessment of opponent, and outcomes in a negotiation experiment. Journal of Management, 20: 605-624.

Kipnis, D. 1972. Does power corrupt? Journal of Personality \& Social Psychology, 24: 33-41. Kolb, D. M., \& Coolidge, G. 1991. Her place at the table. In J. W. Breslin \& J. Z. Rubin (Eds.), Negotiation theory and practice: 261-277. Cambridge, MA: Program on Negotiation, Harvard Law School.

Kramer, R.M., \& Messick, D.M. 1995. Negotiation as a social process: New trends in theory and research. Thousand Oaks, CA: Sage.

Kristof, A, L. 1996. Person-organization fit: An integrative review of its conceptualizations, measurement and implications. Personnel Psychology, 49: 1-49.

Kristof-Brown, A. L., Jansen, K.J., \& Colbert, A. E. 2002. A policy-capturing study of the simultaneous effects of fit with jobs, groups, and organizations. Journal of Applied Psychology, 87: 985-993.

Kristof-Brown, A. L., \& Stevens, C. K. 2001. Goal congruence in project teams: Does the fit between personal mastery and performance goals matter? Journal of Applied Psychology, 86: 1083-1095. 
Kruglanski, A. 1989. Lay epistemics and human knowledge: Cognitive and motivational bases. New York: Plenum.

Laurenceau, J-P., Barret, L. F., \& Pietromonaco, P.R. 1998. Intimacy as an interpersonal process: The importance of self-disclosure, partner disclosure, and perceived partner responsiveness in interpersonal exchanges. Journal of Personality and Social Psychology, 74: 1238-1251.

Lee, K., \& Allen, N.J. 2002. Organizational citizenship behavior and workplace deviance: The role of affect and cognitions. Journal of Applied Psychology, 87: 131-142.

Lord, R.G., \& Brown, D.J. 2004. Leadership processes and follower identity. Mahwah, NJ: Lawrence Erlbaum Associates.

Mannix, E. A. 1994. Will we meet again? The effects of power, distribution norms, and the scope of future interaction in small group negotiation. International Journal of Conflict Management, 5: 343-368.

Mannix, E. A., Tinsley, C. H., \& Bazerman, M. 1995. Negotiating over time: Impediments to integrative solutions. Organizational Behavior and Human Decision Processes, 62: 241251.

Markus, H. R. 1977. Self-schemas and processing information about the self. Journal of Personality and Social Psychology, 35: 63-78.

Markus, H. R., \& Kitayama, S. 1991. Culture and the self: Implications for cognition, emotion, and motivation. Psychological Review, 98: 224-253.

Markus, H. R., \& Kunda, A. 1986. Stability and malleability of the self concept. Journal of Personality and Social Psychology, 51: 50-71.

Markus, H. R., \& Oyserman, D. 1988. Gender and thought: The role of the self-concept. In M. Crawford \& M. Hamilton (Eds.), Gender and thought: 100-127.

Markus, H. R., Smith, J., \& Moreland, R. L. 1985. Role of the self concept in the social perception of others. Journal of Personality and Social Psychology, 49: 1494-1512.

Markus, H. R., \& Wurf, E. 1987. The dynamic self-concept: A social psychological perspective. Annual Review of Psychology, 38: 299-337.

McGinn, K. L., \& Croson, R. 2004. What do communication media mean for negotiators? A question of social awareness. In M. Gelfand \& J. Brett (Eds.) The Handbook of Negotiation and Culture (pp. 334-349). Palo Alto, CA: Stanford University Press.

McGinn, K. L. \& Keros, A. 2002. Improvisation and the logic of exchange in embedded

negotiations. Administrative Science Quarterly, 47: 442-473. McGuire, W. J., McGuire, C. V., \& Cheever, J. 1986. The self in society: Effects of social context on the sense of self. British Journal of Social Psychology, 24: 259-270.

Mikolic, J.M., Parker, J.C., \& Pruitt, D.G. 1997. Escalation in response to persistent annoyance: Group versus individuals and gender effects. Journal of Personality and Social Psychology, 72: 151-163.

Mnookin, R. H., Peppet, S. R., \& Tulumello, A. S. 2000. Beyond winning. Cambridge, MA: Harvard University Press. Moore, D. A., Kurtzberg, T.R., Thompson, L., \& Morris, M. 1999. Long and short routes

to success in electronically-mediated negotiations: Group affiliations and good vibrations. Organizational Behavior and Human Decision Processes, 77: 22-43.

Morris, M. W., \& Gelfand, M. J. 2004. Culture and cognitive dynamics in negotiation. In M. Gelfand \& J. Brett (Eds.), The Handbook of Negotiation and Culture (pp. 45-70). Palo Alto: Stanford University Press.

Morris, M. W., \& Keltner, D. 2000. How emotions work: The social functions of emotional expression in negotiations. In B.M. Staw \& R.I. Sutton (Eds.), Research in organizational behavior (Vol. 11, pp. 1-50). Amsterdam: JAI.

Neale, M.A., \& Bazerman, M.H. 1991. Rationality and cognition in negotiation. New York: Free Press. 
Newcomb, T.M. 1956. The prediction of interpersonal attraction. American Psychologist, 11: 575-586.

Northcraft, G. B., \& Neale, M. A. 1987. Experts, amateurs, and real estate: An anchoring-andadjustment perspective on property pricing decisions. Organizational Behavior and Human Decision Processes, 39: 84-97.

O'Connor, K. M. \& Arnold, J. A. 2001. Distributive spirals: Negotiation impasses and the moderating role of disputant self-efficacy. Organizational Behavior and Human Decision Processes, 84: 148-176.

Olekalns, M., \& Smith, P. L. 2003. Testing the relationships among negotiators' motivational orientations, strategy choices, and outcomes. Journal of Experimental Social Psychology, 39: 101-117.

Organ, D. W. 1988. Organizational citizenship behavior: The good soldier syndrome. Lexington, MA: Lexington.

Parsons, T. 1949. Essays in sociological theory: Pure and applied. New York, NY: The Free Press.

Pinkley, R. 1990. Dimensions of conflict frame: Disputant interpretations of conflict. Journal of Applied Psychology, 75: 117-126.

Pinkley, R. \& Northcraft, G. B. 1994. Conflict frames of reference. Implications for dispute processes and outcomes. Academy of Management Journal, 37: 193-205.

Polzer, J. T., Neale, M. A., \& Glenn, P. O. 1993. The effects of relationships and justifications in an interdependent allocation task. Group Decision and Negotiation, 2: 135-148.

Portes, A. 1998. Social capital: Its origins and applications in modern sociology. Annual Review of Sociology, 22: 1-24.

Pruitt, D.G. 1983. Strategic choice in negotiation. American Behavioral Scientist, 27: 167-194.

Pruitt, D.G., \& Carnevale, P.J. 1993. Negotiation in social conflict. Pacific Grove, CA: Brooks/Cole.

Pruitt, D.G., Carnevale, P.J., Forcey, B., \& Van Slyck, M.V. 1986. Gender effects in negotiation: Constituent surveillance and contentious behavior. Journal of Experimental Social Psychology, 22: 264-265.

Pruitt, D. G., \& Rubin, J. Z. 1986. Social conflict: Escalation, stalemate, and settlement. New York: Random House.

Pugh, S. D. 2002. Emotional regulation in individuals and dyads: Causes, costs and consequences. In R.G. Lord, R.J. Klimoski and R. Kanfer (Eds.), Emotions in the workplace: Understanding the structure and role of emotions in organizational behavior (pp. 147-182). San Francisco: Jossey-Bass.

Rafaeli, A. 1993. Dress and behavior of customer contact employees: A framework for analysis. In T. A. Swartz, D. E. Bowen, \& Brown, S. W. (Eds.), Advances in Services Marketing and Management, Vol. 2 (pp. 175-211). Greenwich, CT: JAI Press.

Rapoport, A.R., \& Chammah, A. 1965. Prisoner's dilemma: A study in conflict and cooperation. Ann Arbor, MI: University of Michigan Press.

Riley, H., \& Babcock, L. 2002. Gender as a situational phenomenon in negotiation. Paper presented at the $15^{\text {th }}$ Annual Conference of the International Association for Conflict Management, Salt Lake City, UT.

Rubin, J.Z. \& Brown, B.R. 1975. The social psychology of bargaining and negotiation. New York: Academic Press.

Sanchez-Burks, J. 2002. Protestant relational ideology and (in) attention to relational cues in work settings. Journal of Personality and Social Psychology, 83: 919-929.

Sanchez-Burks, J., Nisbett, R. E., Ybarra, O. 2000. Cultural styles, relational schemas, and prejudice against outgroups. Journal of Personality and Social Psychology, 79: 174-189.

Schein, E.H. 1985. Organizational culture and leadership. San Francisco: Jossey-Bass.

Schneider, B., White, S., \& Paul, M.C. 1998. Linking service climate and customer perceptions of service quality: Test of a causal model. Journal of Applied Psychology, 83: 150-163. 
Schoeninger, D., \& Wood, W. 1969. Comparision of married and ad hoc mixed-sex dyads negotiating a division of a reward. Journal of Experimental Social Psychology, 5: 483499.

Shah, J., Higgins, E. T., \& Friedman, R. S. 1998. Performance incentives and means: How regulatory focus influences goal attainment. Journal of Personality and Social Psychology, 74: 285-293.

Sherif, M., \& Sherif, C.W. 1969. Social Psychology. New York: Harper and Row.

Shweder, R. A., \& Bourne, E. J. 1982. Does the concept of the person vary cross-culturally? In A. J. Marsella \& G. M. White (Eds.), Cultural conceptions of mental health and therapy (pp. 97-137). Dortrecht, the Netherlands: D. Reidel.

Smith, J.B. 1998. Buyer-seller relationships: Similarity, relationship management, and quality. Psychology \& Marketing, 15: 3-21.

Stillinger, C., Epelbaum, M., Keltner, D., \& Ross, L. 1990. The "reactive devaluation" barrier to conflict resolution. Working paper, Stanford University, Stanford, CA.

Stuhlmacher, A. F., \& Walters, A. E. 1999. Gender differences in negotiation outcomes: A meta-analysis. Personnel Psychology, 52: 653-677.

Swann, W. B. 1987. Identity negotiation: Where two roads meet. Journal of Personality and Social Psychology, 53: 1038-1051.

Swap, W. C., \& Rubin, J. Z, 1983. Measurement of interpersonal orientation. Journal of Personality and Social Psychology, 44: 208-219.

Surrey, J. L. 1991. The "self-in-relation": A theory of women's development. In J. V. Jordan, A. G. Kaplan, J. B. Miller, I. P. Stiver, \& J. L. Surrey (Eds.), Women's growth in connection: Writings from the stone center: 51-66. New York: Guilford Press.

Tajfel, H., \& Turner, J. F. 1979. An integrative theory of intergroup conflict. In W. G. Austin, \& S. Worschel (Eds.), Psychology of intergroup relations (pp. 33-47). Monterey, CA: BrooksCole.

Tajfel, H., \& Turner, J. 1986. The social identity theory of intergroup behavior. In S. Worchel \& W. G. Austin (Eds.) Psychology of intergroup relations ( $2^{\text {nd }}$ ed., pp. 7-25). Chicago: Nelson-Hall.

Talbot, M. 2002. Girls just want to be mean. New York Times Magazine, February 24.

Tedeschi, J.T., Schlenker, B.R., \& Bonoma, T.V. 1973. Conflict, power, and games: The experimental study of interpersonal relations. Chicago: Aldine.

Tenbrunsel, A. E., Wade-Benzoni, K. A., Moag, J., \& Bazerman, M. H. 1999. The negotiation matching process: Relationships and partner selection. Organizational Behavior and Human Decision Processes, 80: 252-283.

Thompson, L. 1998. The mind and heart of the negotiator. Upper Saddle River, NJ: PrenticeHall.

Thompson, L., \& DeHarpport, T. 1998. Relationships, goal incompatibility, and communal orientation in negotiations. Basic and Applied Social Psychology, 20: 33-44.

Thompson, L., \& Hastie, R. 1990. Social perception in negotiation. Organizational behavior and human decision processes, 47: 98-123.

Thompson, L., Medvec, V.H., Seiden, V., \& Kopelman, S. 2001. Poker face, smiley face, and rant and rave: Myths and realities about emotion in negotiation. In M. Hogg \& S. Tindale (Eds.), Blackwell handbook in social psychology (Vol. 3, pp. 139-163), Blackwell, Oxford: UK.

Thompson, L., Neale, M., \& Sinacuer, M. 2004. The evolution of cognition and biases in negotiation research: An examination of cognition, social perception, motivation, and emotion. In M. Gelfand \& J. Brett (Eds.) The Handbook of Negotiation and Culture (pp. 7-44). Palo Alto, CA: Stanford University Press.

Thompson, L., Peterson, E., \& Brodt, S. E. 1996. Team negotiation: An examination of integrative and distributive bargaining. Journal of Personality and Social Psychology, 70: 66-78 
Thompson, L., Peterson, E., \& Kray, L. 1995. Social context in negotiation: An informationprocessing perspective. In R. Kramer and D. Messick (Eds.), Negotiation as a social process (pp. 5-36). New York: Russell-Sage.

Trafimow, D., Triandis, H. C., \& Goto, S. G. (1991). Some tests of the distinction between the private self and the collective self. Journal of Personality and Social Psychology, 60: 649-655.

Triandis, H. C. 1959. Cognitive similarity and interpersonal communication in industry. Journal of Applied Psychology, 43: 321-326.

Triandis, H. C. 1972. The analysis of subjective culture. New York: John Wiley.

Triandis, H. C. 1989. The self and social behavior in differing cultural contexts. Psychology Review, 96: 506-520.

Triandis, H. C., Marin, G., Lisansky, J., \& Betancourt, H. 1984. Simpatia as a cultural script of Hispanics. Journal of Personality and Social Psychology, 47: 1363-1375.

Tsui, A.S., Egan, T.D., \& O'Reilly, C.A. III. 1992. Being different: Relational demography and organizational attachment. Administrative Science Quarterly, 37: 549-579.

Tutzauer, F. and Roloff, M. E. 1988. Communication processes leading to integrative agreements: Three paths to joint benefits. Communication Research, 15: 360-380.

Tversky, A., \& Kahneman, D. 1974. Judgment under uncertainty: Heuristics and biases. Science, 185: 1124-1131.

Valley, K. L, Neale, M. A., \& Mannix, E. 1995. Friends, lovers, colleagues, and strangers: the effects of relationships on the process and outcome of dyadic negotiations. In R. J. Lewicki, B. H. Sheppard, \& R. Bies (Eds.) Research on negotiation in organizations, Vol. 5 (pp. 65-93), Greenwich, CT: JAI Press.

Van Baaren, R. B., Maddux, W.W., Chartrand, T. L., de Bouter, C., \& van Knippenberg, A. 2003. It takes two to mimic: Behavioral consequences of self-construals. Journal of Personality and Social Psychology, 84: 1093-1102.

Van Lange, P.A.M. 1999. The pursuit of joint outcomes an equality in outcomes: An integrative model of social value orientations. Journal of Personality and Social Psychology, 77: 337-349.

Walters, A. E., Stuhlmacher, A. F., \& Meyer, L. L. 1998. Gender and negotiator competitiveness: A meta analysis. Organizational Behavior and Human Decision Processes, 76: 1-29.

Weingart, L. R., \& Olekalns, M. 2004. Communication processes in negotiation: Frequences, sequences, and phases. In M. Gelfand \& J. Brett (Eds.) The Handbook of Negotiation and Culture. Palo Alto, CA: Stanford University Press.

Weingart, L. R., Prietula, M. J., Hyder, E., \& Genovese, C. 1999. Knowledge and the Sequential Processes of Negotiation: A Markov Chain Analysis of Response-in-Kind. Journal of Experimental Social Psychology, 35: 366-393. 